\title{
O SAGRADO EM PRETO E BRANCO: UM RECORTE DA FESTA DE SÃO BENEDITO.
}

\author{
Helio Figueiredo da Serra Netto ${ }^{1}$
}

\begin{abstract}
RESUMO
A festa de São Benedito, conhecida como Marujada, ocorre todo mês de dezembro na cidade de Bragança no estado do Pará. Uma das características estéticas desse evento se manifesta na vestimenta dos devotos, conhecidos como marujos. O chapéu peculiar, a roupa branca, os pés descalços e os detalhes em vermelho (ou azul), criam a identidade dessa manifestação e constituemse como uma expressão imagética única. Ainda que as cores sejam predominantes nessa manifestação cultural, chamando a atenção de grande parte das pessoas que participam da festa, o objetivo deste artigo foi construir uma narrativa fotográfica que fosse além das cores e, ao se construir imagens em preto e branco, procurou-se captar o mais profundo da festa: a relação com o sagrado. Este artigo é um desdobramento de tese de doutorado que buscou refletir sobre a relação com o excesso tecnológico que vivenciamos hoje e como certas imagens podem nos redimir da violência nele embutida. Todas as imagens são de autoria do titular do artigo e foram construídas na Marujada do ano de 2015.
\end{abstract}

Palavras chave: Marujada; Fotografia; Sagrado

\begin{abstract}
The feast of St. Benedict, known as Marujada, occurs every December in the city of Bragança, in the state of Pará, Brazil. One of the aesthetic characteristics of this event is manifested in the dress of devotees, known as sailors. The peculiar hat, the white clothes, the bare feet and the details in red (or blue), create the identity of this manifestation and constitute a singular expression of imagery. Although the colors are predominant in this cultural manifestation, attracting the attention of a great part of the people who participate in the festivity, the objective of this article was to construct a photographic narrative beyond the colors and, when constructing black and white images, we grasp the deepest part of the feast: the relationship with the sacred. This article is an unfolding of doctoral thesis that sought to reflect upon the relationship with the technological excess experienced today, and how certain images can redeem us from the violence embedded in this excess. All images are authored by Helio Figueiredo da Serra Netto and were built in Marujada of 2015.
\end{abstract}

Keywords: Marujada; Photography; Sacred

\section{INTRODUÇÃO}

Uma das questões que nos norteia é a relação eminentemente tecnológica que vivenciamos atualmente, submersos no excesso de imagens e informações, fruto de uma peculiar relação que as tecnologias digitais nos proporcionam, poderemos estar desenvolvendo uma dificuldade cada vez maior de nos relacionar uns com os outros. O que

\footnotetext{
${ }^{1}$ Faculdades Integradas Brasil Amazônia (FIBRA). E-mail: ranehelio@yahoo.com.br
} 
antes era vivido no face-a-face, hoje é intermediado pelas tecnologias, e virtualizamos nossas relações.

$\mathrm{Na}$ tese intitulada "Tal Como Funes: Memória, Hipermemória, Tecnologia e Imagem" (SERRA-NETTO, 2018) trabalhamos com a relação entre a memória, a tecnologia e uma possível disposição que assola o homem contemporâneo que, abarrotado de imagens, cria uma dificuldade de pensar, de se colocar no lugar do outro. Em uma sociedade que cada vez mais importa a aparência, já que a virtualidade preza essencialmente pelo aparente, as pessoas vivem uma onda de violência tecnológica que nos leva a uma cegueira ética (MENDONÇA, 2013) e uma nulificação do outro.

O lado nefasto da tecnologia é algo que vem à baila e tem sido discutido por uma série de intelectuais, principalmente pós segunda guerra mundial, que foi um período intenso de utilização das tecnologias como máquina de Guerra (VIRILIO, 2005) e que se consolidou uma nova era, onde a ubiquidade tecnológica invadiu o planeta, nada mais escapa do poder dos aparelhos.

Entretanto, mesmo diante de uma situação que se sobressai o lado nefasto da tecnologia, podemos experienciar, mesmo em meio ao excesso e ao não pensar, uma relação com a imagem que nos conduz ao oposto, ao diálogo, ao bem, ao sentido da vida. Pensar essa relação foi um dos nossos grandes desafios, mas diríamos, que o desafio maior está justamente em descrevê-la, já que em grande medida se manifesta de forma extremamente subjetiva. Foi pensando nisso que resolvemos lançar mão de um olhar que buscasse se aproximar dessa perspectiva, já que a razão por si só não seria suficiente. Pensamos então que a arte e a poesia poderiam nos ajudar a captar esse olhar. Deste modo, durante algumas manifestações culturais, procuramos focar na relação das pessoas com a tecnologia e com isso construímos ensaios fotográficos que buscassem ressaltar uma relação de sentido entre as pessoas.

Destas manifestações, uma delas nos chamou bastante atenção, a Marujada de São Benedito na cidade de Bragança Pará e no ano de 2015 publicamos o ensaio intitulado "O Milagre das Rosas Vermelhas: corporalidade, fotografia e sacralidade na Marujada de Bragança - Pará” (SERRA-NETTO, 2015). Neste primeiro momento, buscamos fazer uma reflexão sobre a corporalidade, o urbano e as tecnologias e como essa relação refletia a essência da festa que é a glorificação do santo negro, que carrega toda ancestralidade daquele povo, e mais, que se estende além dos limites da cidade. 
Como ficou nítido neste ensaio, o colorido característico da festividade ficou destacado nas imagens, ele faz parte da composição da festa e expressa muito bem o sentimento que emana das pessoas que compõem essa festividade. No entanto, após algumas reflexões, pensamos em como seria fotografar essa festa sem o colorido característico e, se assim, conseguiríamos captar a essência dessa festividade de outra forma, já que a festa emana e respira a sacralidade. E por este motivo, procuramos construir um outro ensaio, mas desta vez com imagens em Preto e Branco, pois gostaríamos de fazer ressaltar aquilo que tem de mais profundo nessa manifestação e como ele está muito além do colorido que a primeira vista nos salta aos olhos.

\section{DESENVOLVIMENTO}

A festa do Glorioso São Benedito acontece todo mês de dezembro na cidade de Bragança, no estado do Pará, é uma das manifestações do catolicismo popular mais importantes do nosso estado que ficou conhecida como "Marujada". Nela podemos ver um número crescente de pessoas, que a cada ano se deslocam em grandes quantidades em busca de agradecimentos, pagamentos de promessa ou mesmo turismo cultural.

A festa é organizada por uma associação de pessoas, conhecidas como Marujos e todo ano um "juiz", como forma de pagamento de promessa, promove a festa com uma contribuição financeira. Ele oferece café da manhã aos Marujos e atua como um tipo de financiador da festa, o que lhe garante um papel de destaque no salão.

Uma das coisas que logo nos chama atenção quando chegamos na cidade de Bragança durante o período da "Marujada" é a vestimenta dos marujos, principalmente o chapéu das mulheres. A festa da "Marujada" inicia-se no dia 16 de dezembro, mas é no seu fechamento no dia 26 que podemos perceber a culminância do evento; neste dia a cor vermelha predomina no traje dos pagadores de promessa e é um dos elementos simbólicos mais importantes dessa manifestação. Embora em outros dias também se use a cor azul, no dia 26 o vermelho evidencia-se em vários lugares, nas roupas, nos adereços, no chapéu estilizado dos marujos e marujas.

O vermelho também expressa o simbolismo da rosa, que na história do santo aparece em um dos seus principais milagres (transformar comida em rosas). São Benedito tinha costume de levar comida do seminário para os pobres e por isso já havia sido repreendido por seus superiores e, em uma dessas situações, ao ser interceptado por um 
deles, transformou a comida que carregava escondido em rosas, para que não fosse repreendido.

Mas não é só o visual que nos chama atenção nessa manifestação, a sonoridade é outro elemento fundamental, a música que orienta o bailar dos marujos no barracão constitui-se como uma junção da sonoridade das castanholas - tocadas pelos marujos -, aliada a rabeca, ao pandeiro, a dança do "retumbão". Será essa junção unida ao colorido da festividade que fundamentará as bases da marujada, o corpo do marujo expressa essa relação, seja na vestimenta, nos adereços, no bailar, na performance encenada. $\mathrm{O}$ "retumbão" desenrola-se como em um grande baile, em que a música, a visualidade, os cheiros nos levam a um tipo de sinestesia, onde os sentidos se confundem, já que as cores, os sons, os cheiros, as imagens interpõem-se e nos fazem adentrar em uma experiência única.

No local conhecido como "barracão", os marujos encontram-se e promovem um baile nos moldes medievais, mas com tonalidades caboclas, a dança em um grande salão, as roupas estilizadas e a divisão entre homens e mulheres que, pacientemente, esperam o momento que irão encontrar um par e dançar em meio ao salão. É lá também que se dá o encontro de gerações, claramente podemos ver pessoas de gerações diferentes, inclusive é comum encontrarmos as mesmas pessoas com o passar dos anos.

Os marujos e marujas apresentam elementos semelhantes em suas vestimentas, como o vermelho e branco que predominam nas cores das roupas e os pés descalços em sinal de pagamento de promessa. Já as castanholas encontram-se presentes nos cintos ou nos dedos dos marujos, que se vestem todo de branco e ostentam alguns detalhes em vermelho ou azul - dependendo do dia. Já as marujas, ostentam contas, terços, colares e "santinhos" que compõem sua corporeidade, sua vestimenta é composta de uma saia vermelha ou azul, acompanhada de uma camisa branca e um chapéu peculiar. O chapéu é uma parte marcante de ambos, mas os das mulheres, confeccionado de pena de pato, com adornos e fitas característicos, chega a ser um espetáculo à parte. $\mathrm{O}$ chapéu das mulheres é feito por encomenda e pode levar meses para ser finalizado, ele é um elemento distintivo desta manifestação cultural.

Nos relatos dessas pessoas a festa gira em torno de promessas e graças alcançadas, ou seja, ela é o resultado da fé em sinal de agradecimento por toda benevolência de São Benedito para com seus fiéis. Assim, todo ano é eleito um novo juiz da festa, pessoa que será responsável por arcar com os custos, que basicamente consiste na produção e na 
alimentação dos marujos que fazem parte da comunidade - este ato também é uma forma de pagamento de promessa. A festividade é fruto de uma relação eminentemente comunitária, mas que ultrapassou completamente os limites físicos dessa comunidade. As pessoas nos contam que a festa e a própria igreja de São Benedito foram construídas com o trabalho dos devotos, principalmente pescadores, sem nenhuma influência das instituições nem estatais e nem da igreja. Mas como a festa foi ganhando notoriedade e proporções, a igreja e os órgãos públicos passaram a fazer parte da organização, pelo menos em parte, já que o foco organizacional central ainda permanece comunitário. Sendo assim, qualquer pessoa pode ser devoto e se tornar marujo, mas somente os marujos cadastrados e contribuintes da comunidade podem dançar no barracão, por exemplo. Essa marca comunitária é um elemento distintivo, pois mesmo que a festa ultrapasse os limites da cidade, com o número considerável de pessoas que se deslocam de outras localidades, o eixo central continua sendo o local.

A cidade de Bragança é caracterizada por um forte vínculo dos seus moradores com o catolicismo popular que se articula com outros tipos de manifestação religiosas - tais como as religiões afro-brasileiras e a pajelança cabocla. A rotina e o fluxo de pessoas na cidade sofrem grande influência das festas de santo e datas sagradas, o elemento de sacralidade é evidente e crucial para o cotidiano bragantino, várias igrejas compõem a arquitetura desta cidade e são rotineiramente frequentadas. Esta cidade tem um viés religioso muito forte, em períodos como sexta feira santa é comum que boa parte da cidade esteja fechada, como comércios e restaurantes em geral, mesmo sendo uma cidade litorânea com traços fortemente turísticos.

Assim então, percebemos como o elemento imagético é algo pungente nesta manifestação, não só no que se refere aos artefatos que compõem o imaginário como nos referimos acima, mas também em relação as tecnologias. Pela grande notoriedade do evento, podemos enxergar uma enxurrada de profissionais de audiovisual, que munidos de seus equipamentos, buscam espaço em meio ao evento para captar suas imagens, mas não só, percebe-se também o uso dessas tecnologias por outras pessoas que fazem parte da festa e os próprios marujos. Vê-se por todo cenário pessoas fotografando entes queridos, situações inusitadas, o baile no barracão e os shows que movimentam a cidade, a tecnologia é algo completamente integrado ao evento e não percebemos ela como algo violento, pois mesmo com um grande número de pessoas fotografando e filmando, o excesso, quando aparece, é de maneira muito sutil, pelo menos no barracão, ponto central de convergência. 
Portanto, a tecnologia não se apresenta como um motivo de desvio do foco das pessoas do motivo principal, a festa, o baile, o santo.

O espaço da tecnologia é também o espaço da comunidade, ele também é um elemento que agrega, porque ele se integra ao tempo do lugar. E o tempo da festa não é o tempo ordinário, é o tempo do sagrado (ELIADE, 2001), o evento nos permitiu uma viagem imaginária, na medida em que literalmente pudemos experienciar o tempo mítico. A convergência de estímulos e, principalmente, a sonoridade da música que acompanha o baile, teve uma grande influência de nos retirar do tempo comum, cronológico e nos levar para tempos imemoriais, por isso a sensação, também, de estarmos em um baile medieval, é como se fossemos transportado para uma outra época. Essa experiência do tempo foi algo que se destacou durante todas as vezes que participamos da festa é algo que foge completamente do ordinário.

Durante o dia 26 de dezembro há diversos eventos, que começam com uma missa matinal, aberta, em frente a igreja de São Benedito, posteriormente os Marujos se encaminham ao barracão e começam a primeira parte do evento, após o almoço inicia-se a procissão e novamente os marujos encaminham-se para o barracão e a festa costuma terminar com um show musical. As pessoas deslocam-se pela cidade de acordo com o movimento da festa, é muito comum percebermos pessoas descansando e desenvolvendo diversos tipos de sociabilidade no local, a cidade literalmente ganha vida, comércios informais e formais desenrolam-se durante este período e permitem uma relação bem dinâmica com a cidade. No baile não há grande preocupação com os passos e com a forma do "retumbão", embora algumas pessoas desempenhem esse papel de forma magnífica, mas grande parte das pessoas permitem se deixar levar pela musicalidade.

Falamos acima da sensação de sair do tempo ordinário, histórico e adentrar no tempo do sagrado, mas sabemos da impossibilidade de expressar essa sensação que consideramos única através de um texto, principalmente porque o elemento principal deste evento está ausente aqui, a imagem sonora, que acreditamos ser ela um fator imprescindível para nos fazer embarcar nessa viagem imaginária. No entanto, utilizaremos de outros recursos para tentar lidar com esta lacuna, tentaremos evocar este som em imagens textuais e fotográficas.

Durante este período, cidade de Bragança torna-se um lugar do imaginário, com um tempo próprio, com uma territorialidade única, com canais imagéticos fluidos, é notória a capacidade que este evento possui de proporcionar uma ligação entre as pessoas e o mundo 
celeste, a música é enaltecedora, as imagens são portais, as tecnologias são meros elementos de subserviência para nos conduzir a essa relação primordial. Para quem circula pelo evento, facilmente pode perceber que nele não cabe a velocidade, porque é preciso que contemplemos, que processemos as imagens que chegam para nós, ali a aura reluz em cada movimento. É preciso que se faça distinção, pelo menos do ponto de vista sonoro, desta festa para outras da região, que em grande parte são conduzidas por elementos sonoros gigantescos conhecidos por "aparelhagens", que literalmente "tremem terra" e tocam os ritmos mais populares da região, como "tecnobrega", "melody", "tecnomelody" e afins. Não queremos com isso entrar em discussões referentes a cultura e identidade sonora, só estamos querendo apontar que (nesse sentido) a festa destoa de grande parte de nossas manifestações culturais, inclusive das festas de santos - vide o ensaio (SERRA-NETTO; MORAES, 2010).

O Santo negro (VIEIRA, 2015) faz referência ao nosso povo, às pessoas que pertencem aquela terra, a vida simples que levam boa parte deles como pescadores, mas que buscam nessa manifestação uma forma de lidar com suas mazelas, de procurar esperança para seus conflitos e preocupações, de quebrar sua rotina, de exaltar o sagrado e com isso suprimir a violência do tempo histórico. E com o intuito de evidenciar isso, procuramos sugerir essa interpretação através de um olhar fotográfico, as imagens foram realizadas durante a festa da Marujada no ano de 2015. Todas as imagens são de nossa autoria, não iremos colocar legenda propositalmente, para deixar que as imagens falem por si, buscamos abrir caminho para a percepção desse imaginário e devemos atentar como nelas se expressam o invisível, o sagrado.

Como foi dito, em um primeiro ensaio (SERRA-NETTO, 2015) optamos por fotografar com imagens coloridas, na medida em que não tínhamos como ignorar a vivacidade da festa e o caráter único que essas cores desempenham neste acontecimento. Já no segundo ensaio, estávamos em busca de algo mais profundo e procuramos traçar um desafio, fotografar em preto e branco uma festa essencialmente colorida, mas assim optamos na tentativa de tentar captar aquilo que tem de mais ancestral nesse evento. Para tal, nos inspiramos em uma deixa importante de Tarkovski, que em seu livro, ao se referir ao seu trabalho, faz uma importante reflexão sobre as cores e a ausência delas em certas imagens. 
tomada, que em geral deve-se apenas à qualidade do filme, é mais um elemento artificial que oprime a imagem, e é preciso fazer alguma coisa para neutralizar essa tendência, se o objetivo for a fidelidade para com a vida. (...) A fotografia em cores entra em conflito com a expressividade da imagem.

(...) Por mais estranho que pareça, embora o mundo seja colorido, a imagem em preto e branco aproxima-se mais da verdade psicológica e naturalista da arte, fundamentada em propriedades especiais da visão e da audição (TARKOVSKIAEI, 2010).

Sabemos que a cor em vários momentos, sim, pode se aproximar dessa verdade, talvez na época em que ele fazia essa reflexão, a imagem ainda tivesse uma conotação de simulação do real muito forte, e por isso essa desconfiança de nos levar a uma falsa verdade. Mas não é só uma questão de busca de verdade, é também uma opção estética, uma tentativa de evidenciar um outro lado da imagem. Mas optamos por assim fazer, na tentativa de ver nessa expressividade o que poderíamos encontrar além das cores, além da vivacidade espetacular, incaptável, inefável, que cuidadosamente tentamos interpretar imageticamente.

Ainda que este não seja o tema do artigo, é importante ressaltarmos algumas questões em relação a composição das imagens a título explicativo. Aqui entenderemos as imagens como texto e, propositalmente, as deixaremos livres de legendas ou numerações, para que elas tenham liberdade no texto e permitam aos leitores uma interpretação livre. A narrativa fotográfica que seguirá é construída com fotos de nossa autoria e que foram captadas no ano de 2015, elas expressam essa busca de evidenciar o imaginário através da imagem fotográfica.

\section{CONCLUSÃO}

Retirar as cores das fotografias da Marujada é também retirar do olhar aquilo que mais o captura, e talvez assim, possamos direcioná-lo para outras coisas da imagem. Quem sabe assim possamos ver além das cores, e procurar aquilo que tem de mais profundo nessa manifestação, quem sabe assim possamos ver o imaginário. 

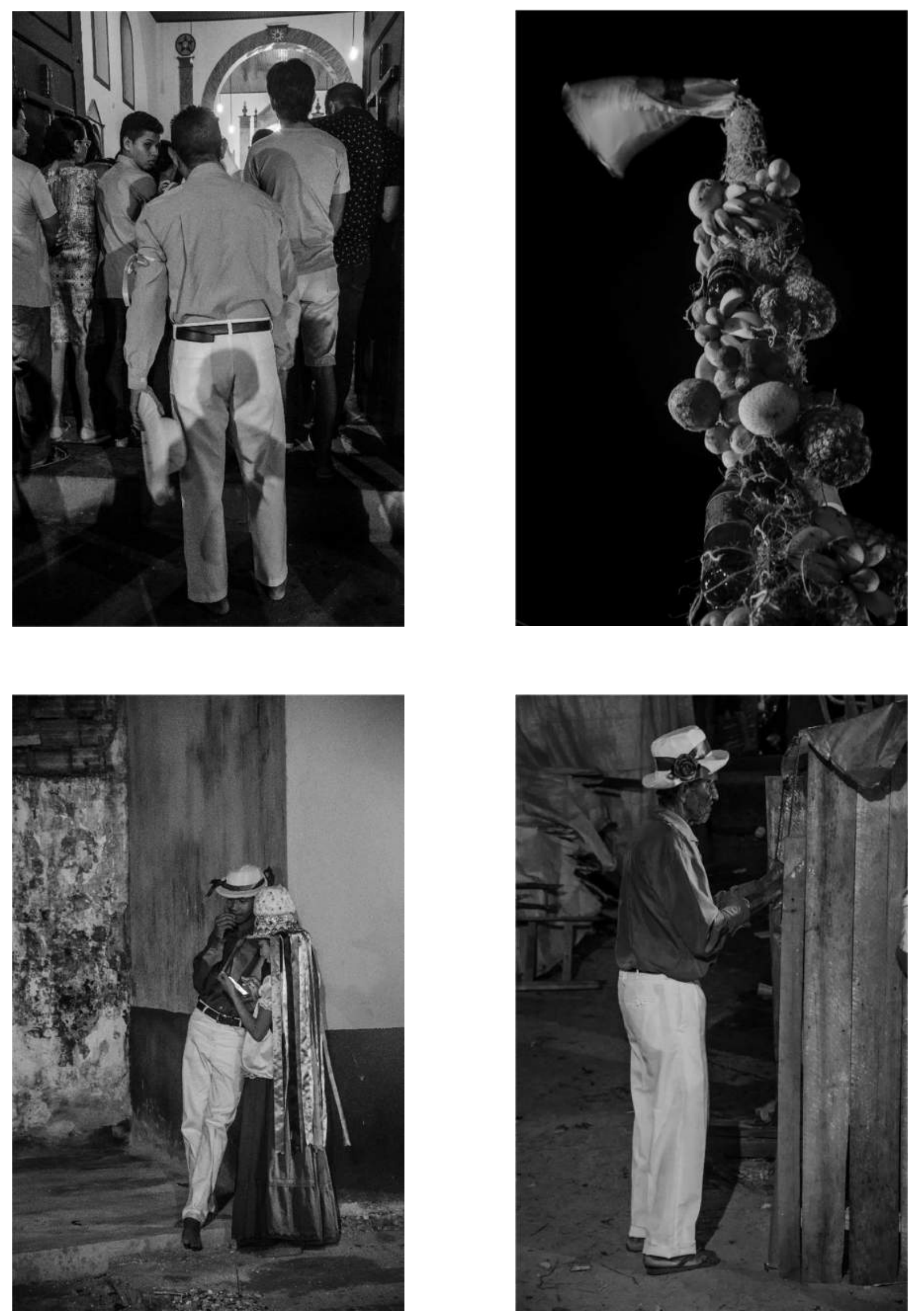

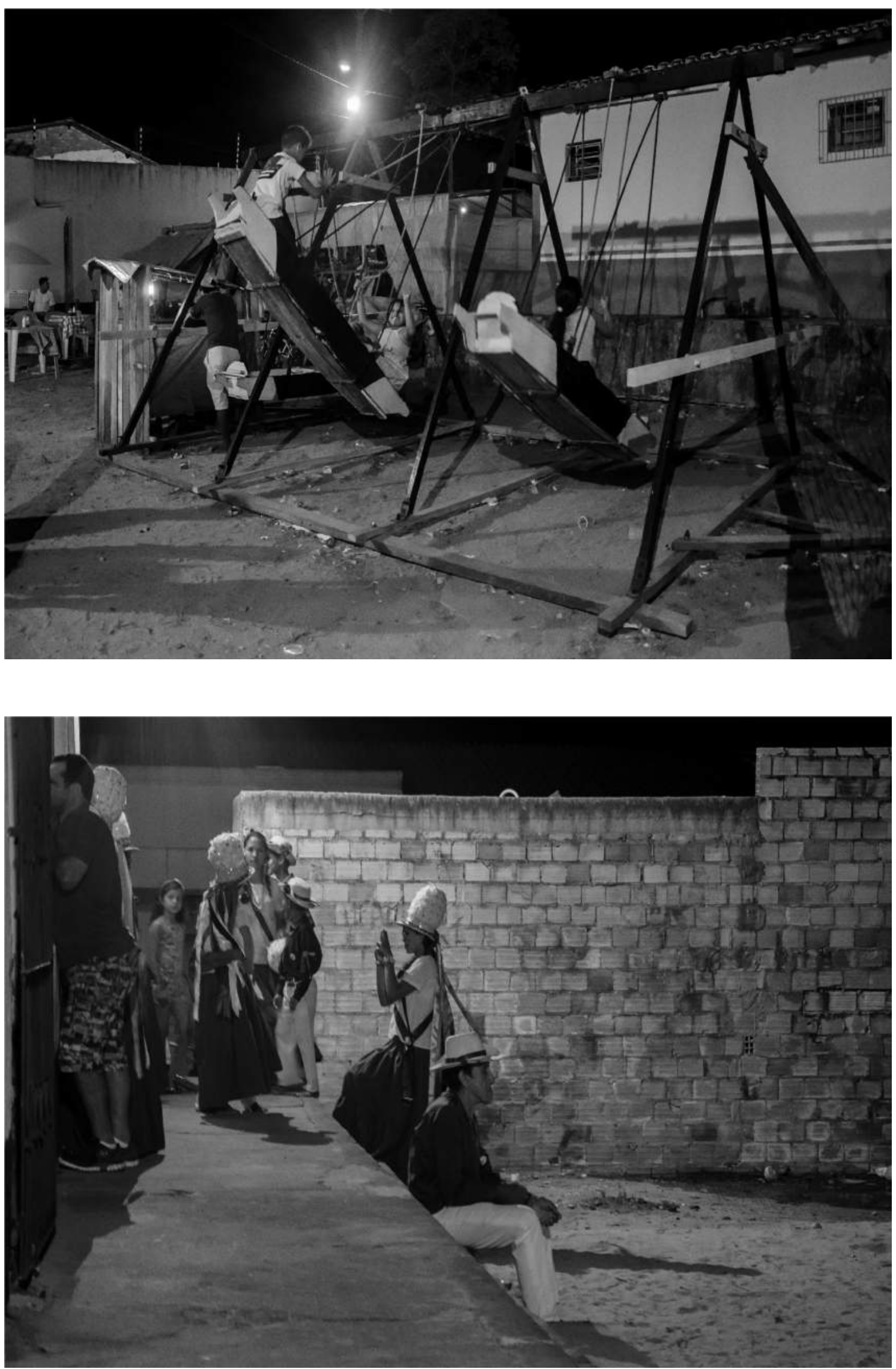

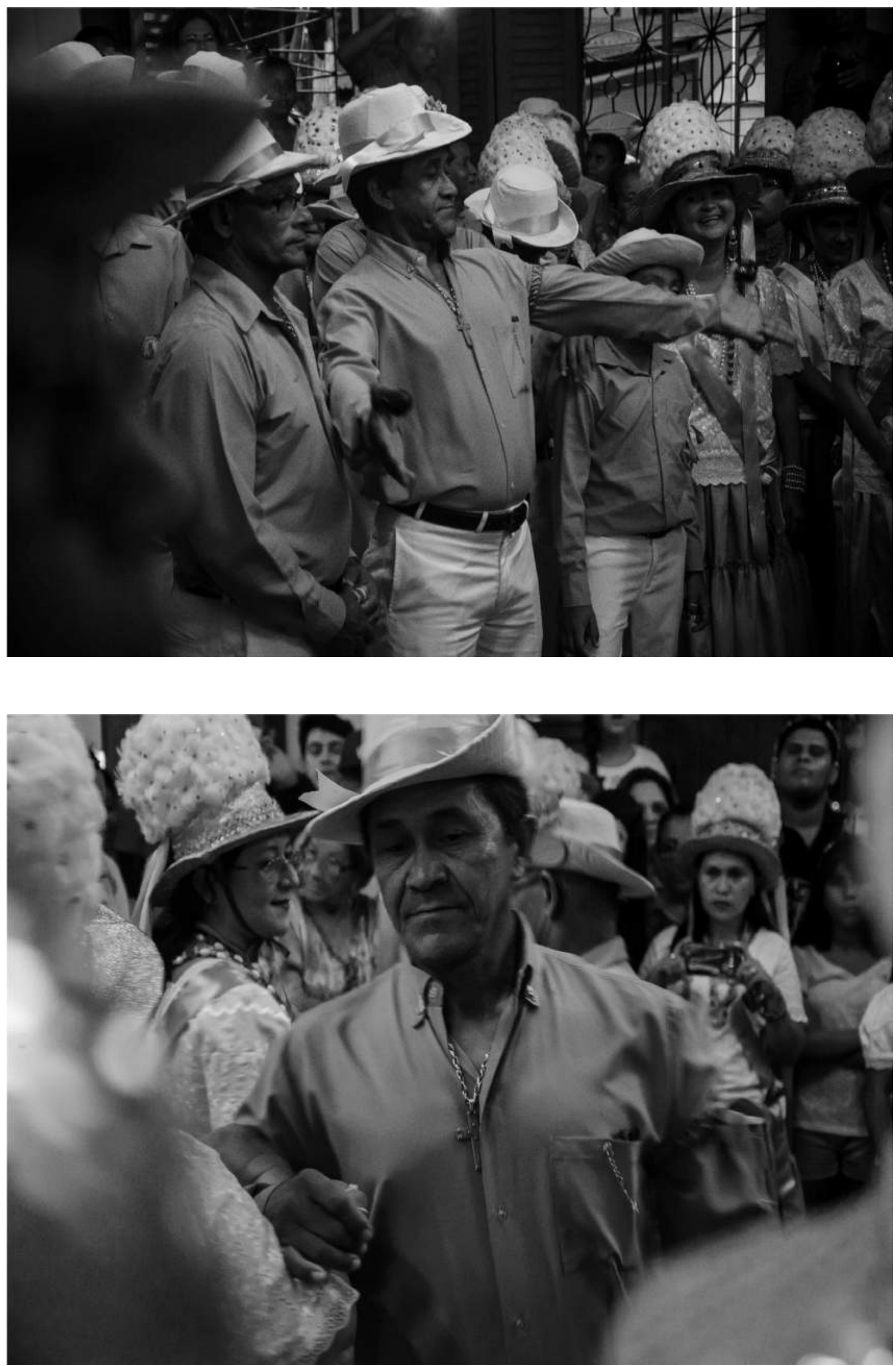


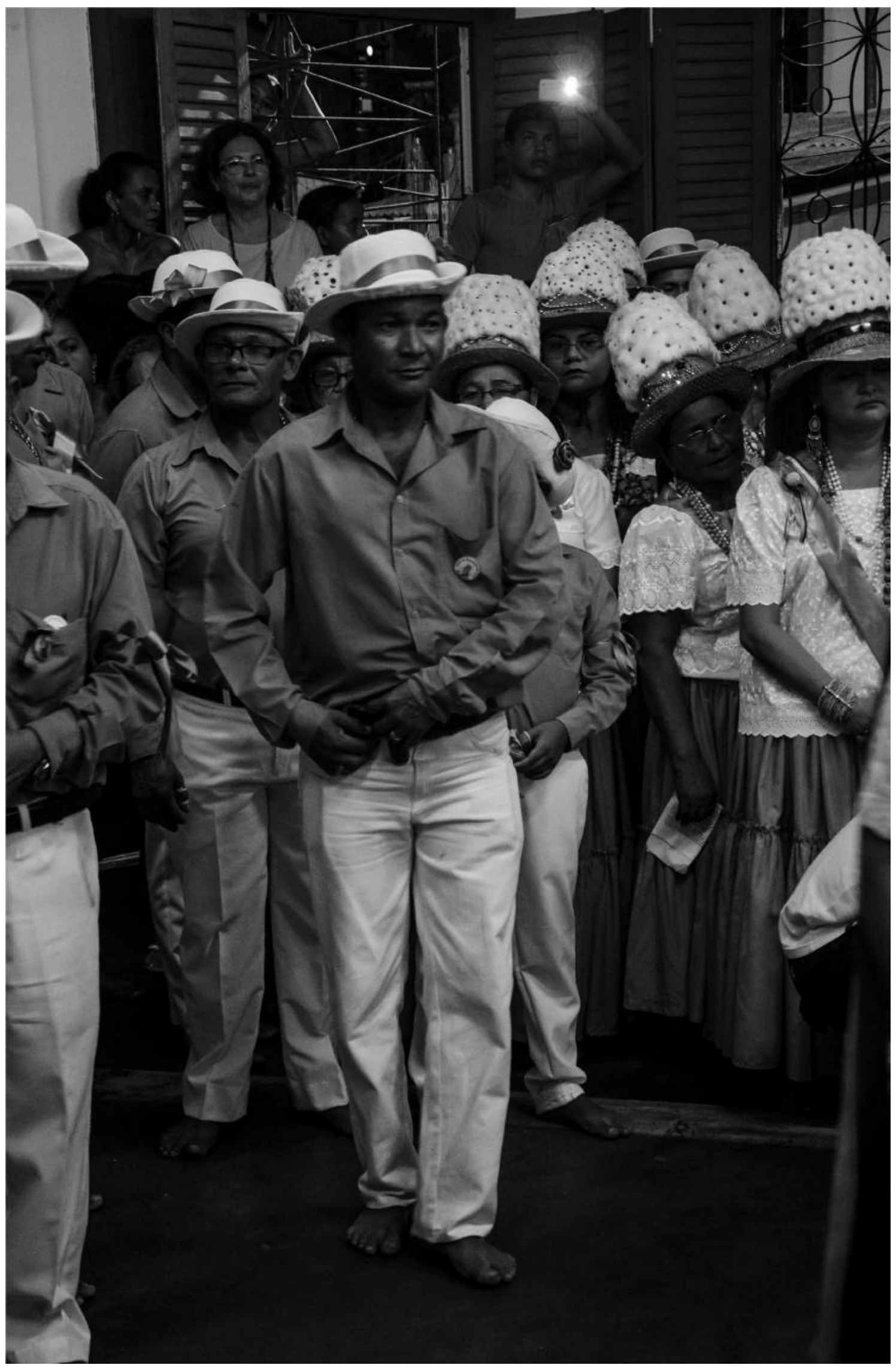



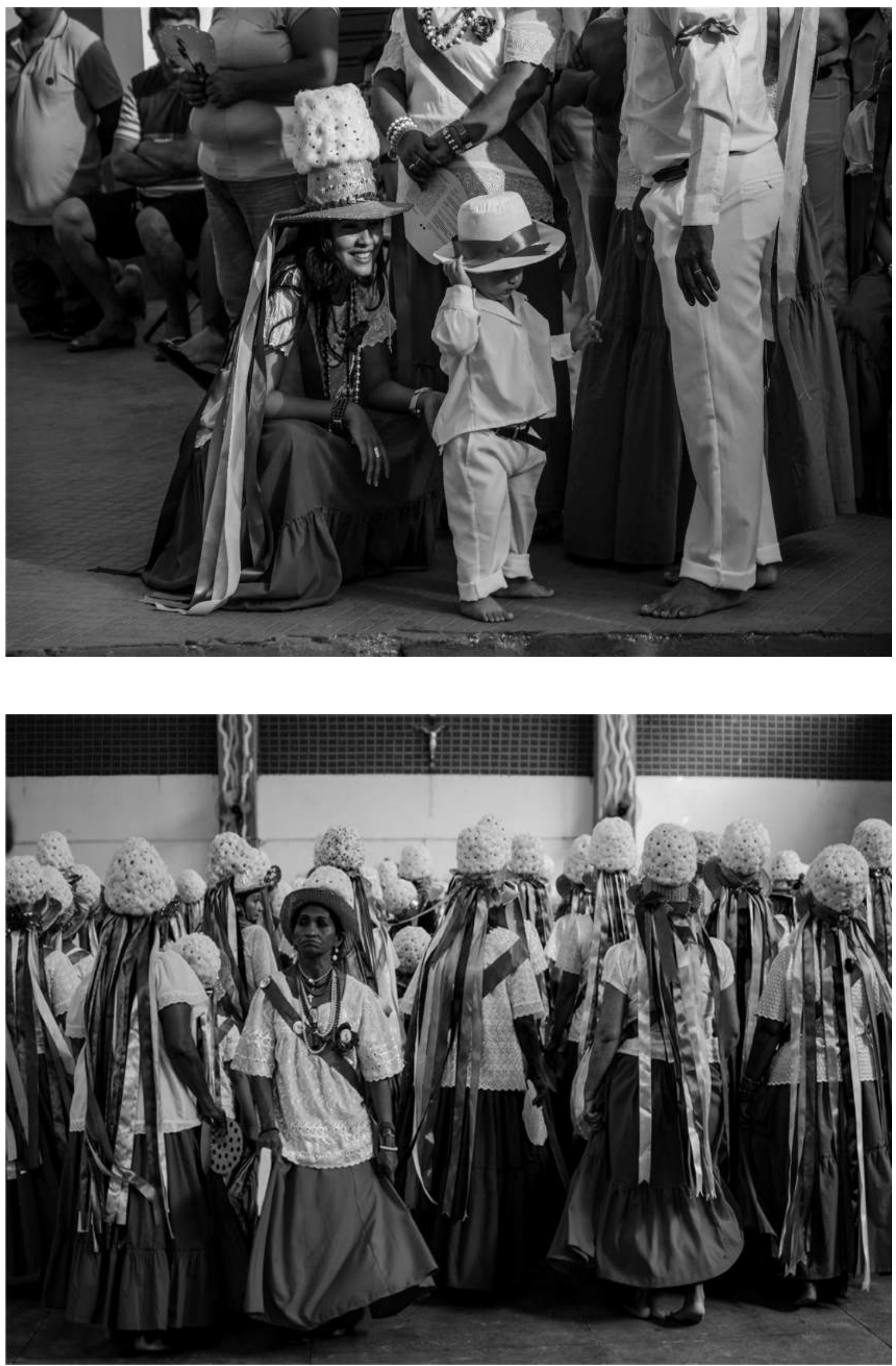











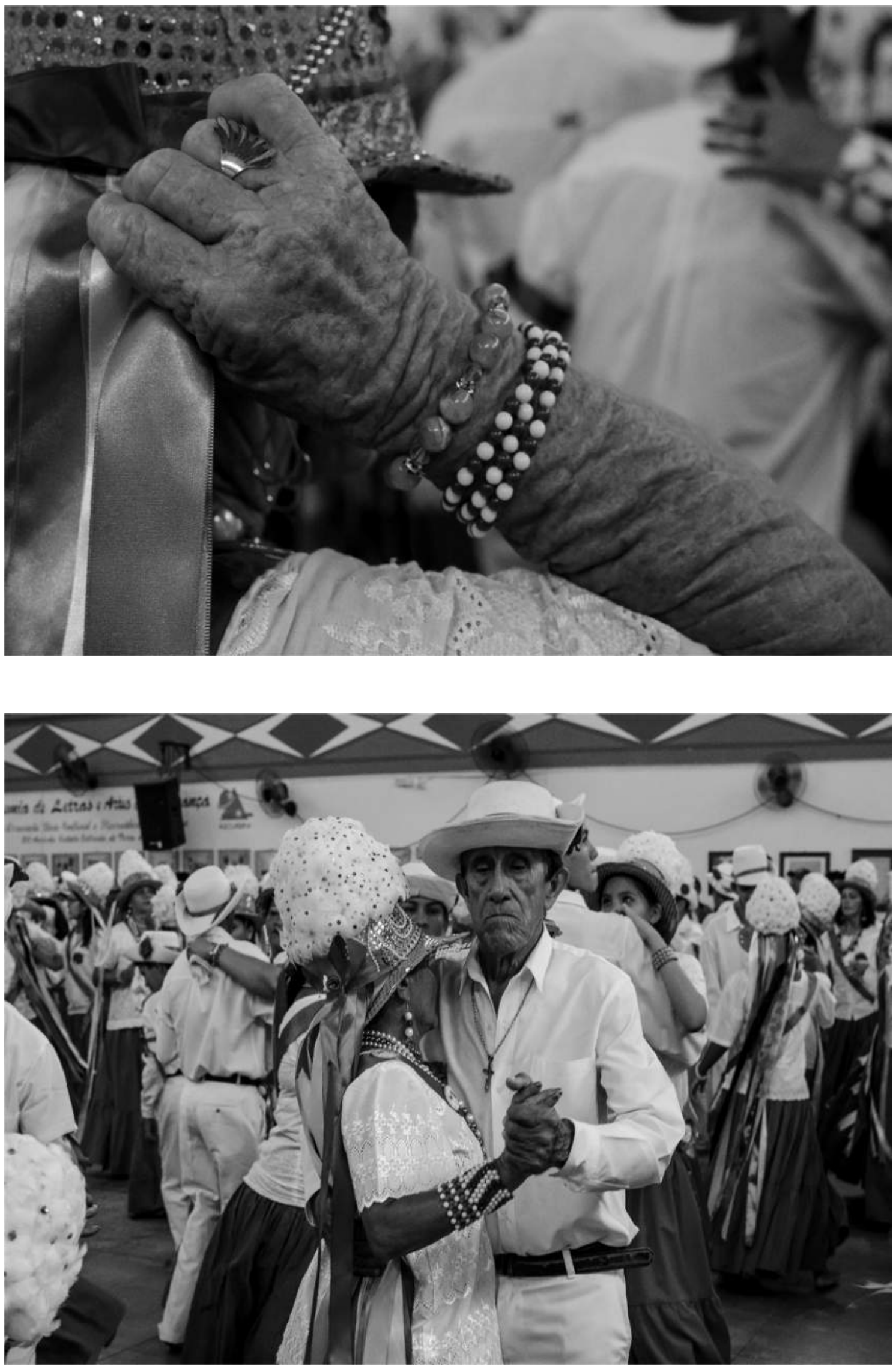

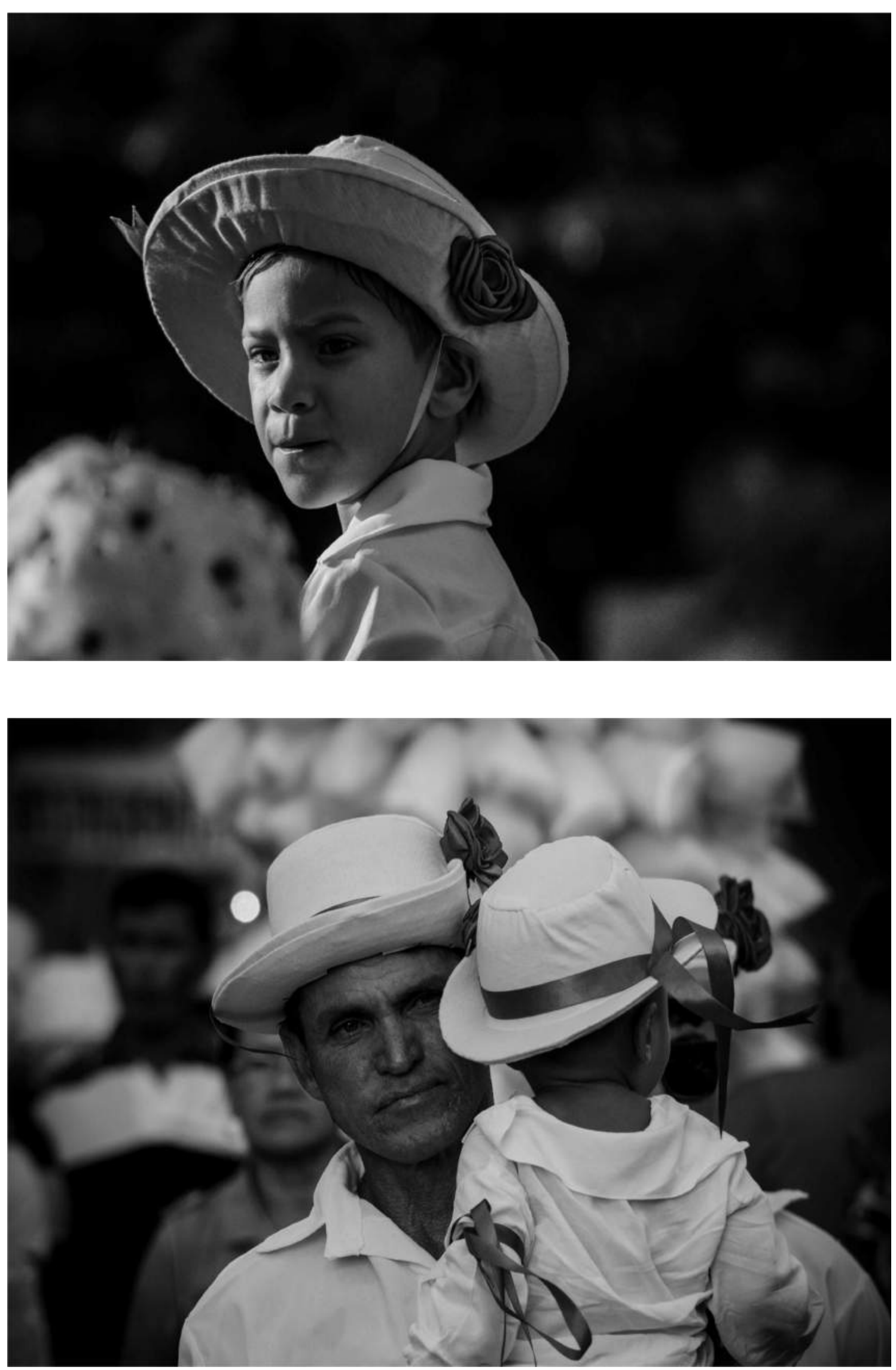




\section{REFERÊNCIAS}

ELIADE, Mircea. O sagrado e o profano: a essência das religiões. São Paulo: Martins Fontes, 2001.

MENDONÇA, Kátia. Televisão: da profusão de imagens à cegueira ética. In: Revista FAMECOS: Mídia, Cultura e Tecnologia. PUC/RS. Porto Alegre. 2013.

SERRA-NETTO. H. F. da "O milagre das rosas vermelhas": corporalidade, fotografia e sacralidade na marujada de Bragança - Pará in: Iluminuras, Porto Alegre, v. 16, n. 37, p.378-388, jan/jun. 2015.

SERRA-NETTO, H. F. da; MORAES, Mônica L. "Que São João Batista Interceda por nós": Fé e Festividade em uma Comunidade Ribeirinha da Amazônia in: Amazônica 2 (1): 172-181. UFPA. Belém - Pará. 2010

SERRA-NETTO, Helio F. S. da. TAL COMO FUNES: Memória, Hipermemória, Tecnologia e Imagem. / Helio F. S. da SERRA- NETTO. - 2018. 278 f. : il. color. Tese (Doutorado) - Programa de Pós-graduação em Sociologia e Antropologia (PPGSA), Instituto de Filosofia e Ciências Humanas, Universidade Federal do Pará, Belém, 2018.

TARKOVSKIAEI, Andreaei Arsensevich. Esculpir o Tempo / Tarkovski: Tradução Jefferson Luiz Camargo. - São Paulo : Martins Martins Fontes, 2010.

VIEIRA, Sônia Cristina de Albuquerque. São Benedito: dos montes de Palermo para os Altares do mundo: a saga de um santo negro. Tese de doutorado defendida pelo PPGSA - UFPA sob orientação da Prof ${ }^{\mathrm{a}}$ Dr$^{\mathrm{a}}$. Angelica Maués. Belém, Pará. 2015.

VIRILIO, Paul. Guerra e Cinema: Logística da Percepção. São Paulo: Boitempo, 2005. 